University of Nebraska - Lincoln

DigitalCommons@University of Nebraska - Lincoln

Faculty Publications, Department of Psychology

Psychology, Department of

2009

Epistatic Interaction Between COMT and DAT1 Genes on Eating

Behavior: A Pilot Study

Samantha L. Hersrud

Black Hills State University

Scott F. Stoltenberg

sstoltenberg2@unl.edu

Follow this and additional works at: https://digitalcommons.unl.edu/psychfacpub

Part of the Psychiatry and Psychology Commons

Hersrud, Samantha L. and Stoltenberg, Scott F., "Epistatic Interaction Between COMT and DAT1 Genes on Eating Behavior: A Pilot Study" (2009). Faculty Publications, Department of Psychology. 382.

https://digitalcommons.unl.edu/psychfacpub/382

This Article is brought to you for free and open access by the Psychology, Department of at DigitalCommons@University of Nebraska - Lincoln. It has been accepted for inclusion in Faculty Publications, Department of Psychology by an authorized administrator of DigitalCommons@University of Nebraska - Lincoln. 


\title{
Epistatic interaction between COMT and DAT1 genes on eating behavior: A pilot study
}

\author{
Samantha L. Hersrud* and Scott F. Stoltenberg ${ }^{\dagger}$ \\ * Black Hills State University, Department of Biology, 1200 University Street, Spearfish, SD 57799, USA; present address: Physician Scientist Pro- \\ gram, Sanford School of Medicine of The University of South Dakota, 414 East Clark Street, Vermillion, SD 57069, USA \\ † Black Hills State University, Department of Psychology, 1200 University Street, Spearfish, SD 57799, USA; present address: Department of Psy- \\ chology, University of Nebraska-Lincoln, Lincoln NE, USA
}

Corresponding author - S. F. Stoltenberg

\begin{abstract}
Problems related to food and weight in women may be influenced by the (DA) dopamine system. Catechol-o-methyl transferase (COMT) and the dopamine transporter (DAT) exert control on concentrations of extracellular DA. High and low functioning alleles of the COMT Val158Met and DAT1 3' UTR VNTR polymorphisms have been identified, and their associations with reward and cognition suggest a role in the modulation of eating behavior. A sample of undergraduate college women $(N=71)$ was characterized for binge eating and eating psychopathology and genotyped for the COMT and DAT1 markers. Results revealed a significant epistatic interaction between COMT and DAT1 genes on eating psychopathology and binge eating ( $p=.02$ for both). This suggests that genetic studies of risk for maladaptive eating behavior involving the dopamine system should explicitly consider epistasis.
\end{abstract}

Keywords: catechol-o-methyl transferase, dopamine transporter, eating disorders, epistasis

\section{Introduction}

Eating disorders (EDs) are not uncommon in women and are influenced by genes (Bulik, Sullivan, Wade, \& Kendler, 2000). The role of dopamine (DA) on food intake (Palmiter, 2007) and on the regulation of potential ED endophenotypes (altered reward processing and cognitive deficits) (Bilder, Volavka, Lachman, \& Grace, 2004; Roberts, Tchanturia, Stahl, Southgate, \& Treasure, 2007; Wagner et al., 2007; Yacubian et al., 2007) suggests that DA is a good candidate system for ED research.

The gene for the DA degrading enzyme catechol-o-methyltransferase (COMT) has a polymorphism in codon 158 that substitutes a methionine for a valine amino acid (Val158Met), producing a less active enzyme and increased extracellular DA concentrations (Lachman et al., 1996). Divergent cognitive phenotypes have been suggested for the Met and Val alleles-efficient and focused versus flexible yet easily distracted, respectively (Bilder et al., 2004). The gene encoding the DA reuptake transporter (DAT) has a variable number tandem repeat (VNTR) polymorphism in the $3^{\prime}$ untranslated region (UTR) that most commonly produces 9 and 10 repeat alleles (Vandenbergh et al., 1992). The 10 allele is thought to produce greater overall DAT activity and a corresponding increase in DA reuptake (Heinz et al., 2000). The 10-repeat allele is associated with impulsivity (Cornish et al., 2005), whereas the 9-repeat allele is associated with low novelty seeking (Sabol et al., 1999). The influence of COMT and DAT on eating behavior has not been fully characterized (Hosak, 2007; Shinohara et al., 2004).

We are not aware of any eating behavior studies reporting DA system epistasis; however, there are reports of epistatic and additive effects of Val158Met and DAT1 VNTR on reward processing and cognition (Bertolino et al., 2006; Caldu et al., 2007; Yacubian et al., 2007). We hypothesized an epistatic or additive influence of Val158Met and DAT1 VNTR on disordered eating in women.

\section{Methods}

We report on the subsample of college age women $(N=92)$ who were part of a pilot study of health-risk behaviors including both genders $(N=156)$. Local institutional review boards approved this study. To protect privacy, subjects did not sign any documents but gave documented, voluntary oral consent.

Participants completed the Eating Disorder Examination Questionnaire (EDE-Q) (Fairburn \& Beglin, 1994), a 38-item self-reporting version of the Eating Disorder Examination, which has been used in populations of college women (Luce, Crowther, \& Pole, 2008). The first section used a 7-point Likert-scale adjusted to a 6-point scale for convenience. We did not expect this to affect the data because we sought to compare eating psychopathology among individuals, not to make clinical diagnoses. The last section required yes or no answers regarding specific eating behaviors. Responses focused on the past 28 days. We analyzed the global score, which indexed overall severity of eating psychopathology. The bingeeating measure was taken from an item in the first section, "Have you had any episodes of binge-eating?" with instructions to define binge-eating as consuming an unusually large quantity of food with loss of control. Meal size score was calculated from an item in the second section, "Have there been times when you have eaten what most people would regard as an unusually large amount of food?" 
Buccal cells were collected and DNA was extracted from them with the DNeasy Blood \& Tissue Kit (Qiagen). Polymerase chain reaction genotyping was performed as previously described for COMT (Ruiz- Sanz, Aurrekoetxea, Ruiz del Agua, \& Ruiz-Larrea, 2007) and DAT1 (Shinohara et al., 2004).

Exclusion criteria included missing responses (6), insufficient DNA sample (3), non-Caucasian self-reported race/ethnicity (7), age greater than 31 (5). The binge-eating score was dichotomized due to the leftward skew in the frequency distribution, and the meal size score was naturally dichotomous. Correlation matrixes comparing binge eating, meal size, and EDE-Q global scores were assessed using two-tailed Spearman's rank correlations, and $p$-values were Bonferroni adjusted. EDE-Q scores were compared using full-factorial analysis of variance (ANOVA) with COMT and DAT1 genotypes as fixed effects. Binge eating was compared using full-factorial logistic regression with COMT and DAT1 genotypes coded as dummy variables. Output was corrected for multiple testing with the Bonferroni-Holm step-wise method. For DAT1, a low number of 9/9 homozygotes necessitated their grouping with the heterozygotes (Sabol, 1999 \#226). For COMT, analyses first were conducted using an additive model with a threelevel genotype grouping (Met/Met, Met/Val, Val/Val). If the additive model was not significant, both dominance models would be compared using Akaike's information criterion (AIC) for ANOVA or the Log Likelihood of Constants Only Model (LLO) for logistic regression analyses.

\section{Results}

The final sample was comprised of 71 women. age range 18-31; mean (S.D.) 20.56 (2.73). Genotype frequencies were in Hardy-Weinberg equilibrium. Our scale adjustment did not bias data, as global scores were consistent with other normal undergraduate populations [our data: $M$ (S.E.) $=1.63(0.12)$ : Luce et al. (2008): $M$ (S.E.) $=1.73$ (0.05): $t=0.61, p=.5]$. Bingeeating was correlated with EDE-Q scores $(\rho=.31, p=.01)$. Meal size scores were not correlated with EDE-Q scores $(\rho=.25, p>$ $.05)$ or binge eating $(\rho=.06, p>.05)$. Difficulty has been noted in discriminating between binge eating and merely eating a large quantity of food (Wilfley, Schwartz, Spurrell, \& Fairburn, 1997). A lack of correlation between the meal size and binge eating variables and the greater frequency of reported overeating episodes compared to binge eating episodes (54\% vs. 39\%, respectively) suggests that participants distinguished between the measures, although the difference in frequencies was only moderately significant $(p<.1)$.

The ANOVA model with DAT1 genotype. additive COMT genotype, and the gene $\times$ gene interaction accounted for $13 \%$ of the variance in EDE-Q global scores (Squared Multiple R). No main effects were observed, but the two-way interaction (COMT * DAT1) was significant after correction for multiple testing $[F(1,65)=4.20, p=.02]$ (Table 1.) The highest mean EDE-Q global scores associated with the Met/Met, 10/10 [ $n$ $=8 ; M$ (S.D.) $=2.35$ (1.15) $]$ and Val/Val. 9/_ $[n=6 ; M$ (S.D.) $=2.14(0.80)]$ genotypes, and the lowest mean EDE-Q global scores associated with the Met/Met, 9/_ $[n=8 ; M$ (S.D.) $=1.16$ (0.68)] and Val/Val 10/10 [ $n=7: M$ (S.D.) $=1.30(0.80)]$ genotypes (Figure 1 ).

The logistic regression analysis for binge-eating with DAT1 genotype, additive COMT genotype, and the gene $\times$ gene interaction was not significant $[\mathrm{LL}(0)=-47.62, \mathrm{G}=(d f=5) 7.59, p=.20]$,
Table 1. ANOVA and logistic regression analyses for eating psychopathology and binge eating.

\begin{tabular}{|c|c|c|c|c|c|c|c|}
\hline \multirow[b]{2}{*}{ Variable } & \multicolumn{3}{|c|}{$\begin{array}{l}\text { Eating } \\
\text { psychopathology }\end{array}$} & \multicolumn{2}{|c|}{$\begin{array}{l}\text { Binge } \\
\text { eating }\end{array}$} & \multirow[b]{2}{*}{ Z } & \multirow[b]{2}{*}{$P$} \\
\hline & $d f$ & $F$ & $P$ & $B$ & SE $B$ & & \\
\hline COMT & 2 & 0.35 & .7 & 1.86 & 1.14 & 1.63 & .1 \\
\hline DAT1 & 1 & 0.26 & .6 & 2.49 & 1.38 & 1.80 & .07 \\
\hline COMT $\times$ DAT 1 & 12 & 4.20 & .02 & -3.52 & 1.49 & -2.36 & .02 \\
\hline Residual & 65 & & & & & & \\
\hline
\end{tabular}

COMT $=$ catechol-o-methyltransferase gene, DAT1 = dopamine transporter 1 gene. Analysis of Variance (ANOVA) for eating psychopathology is defined by mean Eating Disorder Examination Questionnaire global scores with an additive model COMT grouping (Met/Met, Met/ Val, Val/Val). Logistic regression data is reported for the Met dominant model with COMT grouping Met/-, Val/Val. Binge eaters were defined as reporting at least one binge episode in the last 28 days.

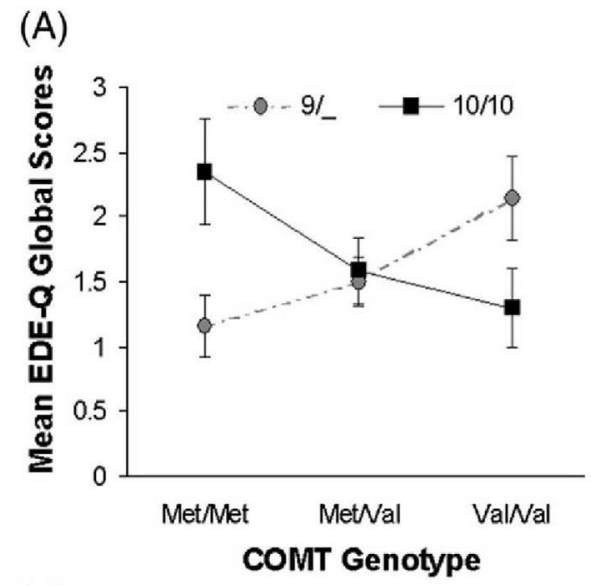

(B)

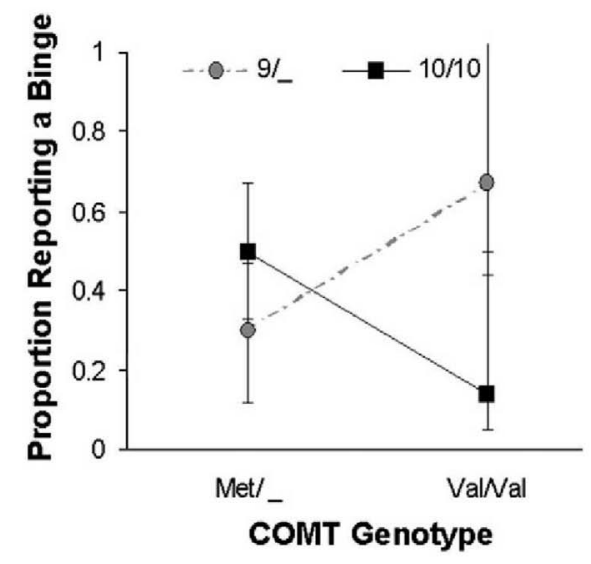

Figure 1. Graphs show epistasis between COMT (catechol-o-methyltransferase) and DAT1 (dopamine transporter 1) genes and associations with eating behavior outcomes. (A) Lines representing DAT1 genotypes (9/_ and 10/10) show the change in mean EDE-Q (Eating Disorder Examination Questionnaire) global scores across COMT genotypes with standard error bars. Increasing COMT activity, from Met/ Met to $\mathrm{Val} / \mathrm{Val}$, corresponded to increasing EDE-Q global scores in 9/_ individuals but decreasing scores in 10/10 individuals $(p=.02)$. (B) Lines representing DAT1 genotypes (9/_ and 10/10) show the change in proportion of individuals reporting binge eating across COMT genotypes with error bars reflecting $95 \%$ confidence intervals. Increasing COMT activity, from Met/_ to Val/Val, corresponded to an increasing likelihood of binge eating in 9/_ individuals but a decreasing likelihood of binge eating in 10/10 individuals $(p=.02)$. 
therefore both dominance models were tested. No main effects were observed, but the Met dominant model was significant for the interaction term (COMT * DAT1) after correction for multiple testing $(z=-2.36, p=.02)$, was a better fit than the Val dominant model [Met dominant: $\operatorname{LL}(0)=-47.62, G=$ $(d f=3) 7.52, p=.06$; Val dominant: $\operatorname{LL}(0)=-47.62, G=(d f=3)$ $1.50, p=.70]$, and accounted for $14 \%$ of the variance in binge eating (Nagelkerke's $R^{2}$ ) (Table 1.) The trend was consistent with that seen with EDE-Q global scores - the pairing of the Met and 10 alleles and the Val and 9 alleles associated with the highest mean scores and the greatest odds of reporting a binge eating episode [odds ratio $(95 \% \mathrm{CI})=33.75(1.81,629)]$, while the Met and 9 alleles and the Val and 10 alleles were associated with the lowest mean scores and the lowest odds of reporting a binge eating episode [odds ratio $(95 \% \mathrm{CI})=0.003$ $(0.002, .055)]$ (Figure 1).

\section{Discussion}

This is the first report of epistasis between COMT and DAT1 genes on eating behavior. Specifically, the Met/10 and Val/9 genotypes were associated with elevated binge eating and eating psychopathology. Previous studies of the interaction between COMT and DAT1 genes reported these genotypes to be associated with altered reward sensitivity and cognitive function. This supports our findings in that persons with food and weight problems have deficits in cognition and reward processing compared to normal controls as cited above. This and the work of others (e.g. Bilder et al., 2004) suggests that Val158Met and DAT1 VNTR interact to produce two alternative phenotypes susceptible to disordered eating-one characterized by an understimulated reward system and cognitive rigidity (Met/10; too little COMT activity and too much DAT activity) and the other characterized by an overactive reward system and impulsive distractibility (Val/9; too much COMT activity and too little DAT activity).

Despite a relatively small sample size, there are several strengths to this pilot study. First, the homogenous nature of the sample population decreases the chance that our findings are attributable to population structure. Second, that results were consistent with prior research makes it less likely that the observed patterns were due to chance alone. And third, our $p$-values survived correction for multiple testing. We are currently conducting a follow-up study $(N=500)$ to examine the influence of genetic variation on health-risk behaviors including disordered eating. Although DA therapy already is used to treat behavioral disorders, a better understanding of the influence of COMT and DAT1 genes could improve its effectiveness. The proper course of treatment eventually might be determined non-invasively through genotyping.

\section{Acknowledgments}

This study was made possible by NIH Grant Number 2 P20 RR016479 and 1 R15MH077654-01A1.

\section{References}

Bertolino, A., Blasi, C., Latorre, V., Rubino, V., Rampino, A., Sinibaldi, L., et al. (2006). Additive effects of genetic variation in dopamine regulating genes on working memory cortical activity in human brain. Journal of Neuroscience 26(15), 3918-3922.
Bilder, R. M., Volavka, J., Lachman, H. M., \& Grace, A. A. (2004). The catechol-o-methyltransferase polymorphism: Relations to the tonic-phasic dopamine hypothesis and neuropsychiatric phenotypes. Neuropsychopharmacology 29(11), 1943-1961.

Bulik, C. M., Sullivan, P. F., Wade, T. D., \& Kendler, K S. (2000). Twin studies of eating disorders: A review. International Journal of Eating Disorders 27(1), 1-20.

Caldu, X., Vendrell, P., Bartres-Faz, D., Clemente, I., Bargallo, N., Jurado, M. A., et al. (2007). Impact of the COMT Val108/158 Met and DAT genotypes on prefrontal function in healthy subjects. NeuroImage 37(4), 1437-1444.

Cornish, K. M., Manly, T., Savage, R., Swanson, J., Morisano, D., Butler, N., et al. (2005). Association of the dopamine transporter (DAT1) 10/10-repeat genotype with ADHD symptoms and response inhibition in a general population sample. Molecular Psychiatry, 70(7), 686-698.

Fairburn, C. G., \& Beglin, S. J. (1994). Assessment of eating disorders: Interview or self-report questionnaire? International Journal of Eating Disorders 76(4), 363-370.

Heinz, A., Goldman, D., Jones, D. W., Palmour, R., Hommer, D., Gorey, J. C., et al. (2000). Genotype influences in vivo dopamine transporter availability in human striatum. Neuropsychopharmacology 22(2), 133-139.

Hosak, L. (2007). Role of the COMT gene Val158Met polymorphism in mental disorders: A review. European Psychiatry 22(5), 276-281.

Lachman, H. M., Papolos, D. F., Saito, T., Yu, Y., Szumlanski, C. L., \& Weinshilboum, R. M. (1996). Human catechol-o-methyltransferase pharmacogenetics: Description of a functional polymorphism and its potential application to neuropsychiatric disorders. Pharmacogenetics 6(3), 243-250.

Luce, K. H., Crowther, J. H., \& Pole, M. (2008). Eating Disorder Examination Questionnaire (EDE-Q): Norms for undergraduate women. International Journal of Eating Disorders 41(3), 273-276.

Palmiter, R. D. (2007). Is dopamine a physiologically relevant mediator of feeding behavior? Trends in Neurosciences 30(8), 375-381.

Roberts, M. E, Tchanturia, K., Stahl, D., Southgate, L., \& Treasure, J. (2007). A systematic review and meta-analysis of set-shifting ability in eating disorders. Psychological Medicine 37(8), 1075-1084.

Ruiz-Sanz, J. I., Aurrekoetxea, I., Ruiz del Agua, A., \& Ruiz-Larrea, M. B. (2007). Detection of catechol-o-methyltransferase Val158Met polymorphism by a simple one-step tetra-primer amplification refractory mutation system-PCR. Molecular and Cellular Probes 27(3), 202-207.

Sabol, S. Z., Nelson, M. L, Fisher, C., Gunzerath, L., Brody, C. L., Hu, S., et al. (1999). A genetic association for cigarette smoking behavior. Health Psychology 18(1), 7-13.

Shinohara, M., Mizushima, H., Hirano, M., Shioe, K., Nakazawa, M., et al. (2004). Eating disorders with binge-eating behaviour are associated with the s allele of the 3'-UTR VNTR polymorphism of the dopamine transporter gene. Journal of Psychiatry and Neuroscience 29(2), 134-137.

Vandenbergh, D. J., Penico, A. M., Hawkins, A. L., Griffin, C. A., Li, X., Jabs, E. W., et al. (1992). Human dopamine transporter gene (DAT1) maps to chromosome 5p15.3 and displays a VNTR. Genomics 14(4), 1104-1106.

Wagner, A., Aizenstein, H., Venkatraman, V. K., Fudge, J., May, J. C., Mazurkewicz. L., et al. (2007). Altered reward processing in women recovered from anorexia nervosa. American Journal of Psychiatry 164(12), 1842-1849.

Wilfley, D. E., Schwartz, M. B., Spurrell, E. B., \& Fairburn, C. G. (1997). Assessing the specific psychopathology of binge eating disorder patients: Interview or self-report? Behaviour Research and Therapy 35(12), 1151-1159.

Yacubian, J., Sommer, T., Schroeder, K., Glascher, J., Kalisch, R., Leuenberger, B., et al. (2007). Gene-gene interaction associated with neural reward sensitivity. Proceedings of the National Academy of Sciences USA 104(19), 8125-8130. 